\title{
The improvement of right ventricular function after adenotonsillectomy in children with obstructive sleep apnea
}

\author{
Dong Yeop Kim, MD, Kyung Ok Ko, MD, PhD, Jae Woo Lim, MD, Jung Min Yoon, MD, Young Hwa Song, MD, Eun Jung Cheon, MD \\ Department of Pediatrics, Konyang University College of Medicine, Daejeon, Korea
}

Purpose: Adenotonsillar hypertrophy (ATH) that causes upper airway obstruction might lead to chronic hypoxemic pulmonary vasoconstriction and right ventricular (RV) dysfunction. We aimed to evaluate whether adenotonsillectomy (T\&A) in children suffering from obstructive sleep apnea (OSA) due to severe ATH could improve RV function.

Methods: Thirty-seven children (boy:girl=21:16; mean age, 9.52 \pm 2.20 years), who underwent T\&A forsleep apnea due to ATH, were included. We analyzedthe mean pulmonary artery pressure (mPAP), the presence and the maximal velocity of tricuspid regurgitation (TR), the tricuspid annular plane systolic excursion (TAPSE), and the right ventricular myocardial performance index (RVMPI) with tissue Doppler echocardiography (TDE) by transthoracic echocardiography pre- and post-T\&A. The follow-up period was $1.78 \pm 0.27$ years.

Results: Only the RVMPI using TDE improved after T\&A (42.18 \pm 2.03 vs. $40 \pm 1.86, P=0.001)$. The absolute value of TAPSE increased ( $21.45 \pm 0.90 \mathrm{~mm}$ vs. $22.30 \pm 1.10 \mathrm{~mm}, P=0.001$ ) but there was no change in the $z$ score of TAPSE pre- and post-T\&A (1.19 \pm 0.34 vs. $1.24 \pm 0.30, P=0.194)$. The mPAP was within normal range in children with $A T H$, and there was no significant difference between pre- and post$T \& A(19.6 \pm 3.40$ vs. $18.7 \pm 2.68, P=0.052)$. There was no difference in the presence and the maximal velocity of $\operatorname{TR}(P=0.058)$.

Conclusion: RVMPI using TDE could be an early parameter of RV function in children with OSA due to ATH.

Key words: Obstructive sleep apnea, Adenotonsillectomy, Myocardial performance index of the right ventricle

\section{Introduction}

Adenotonsillar hypertrophy (ATH) is relatively common in childhood, but severe ATH often causes obstructive sleep apnea (OSA), which is characterized by repetitive episodes of paused breathing during sleep typically last 20 to 40 seconds ${ }^{1)}$ by complete and partial obstruction of the upper airway. Persistent OSA might cause chronic hypoxemia and hypercarbia, which can lead to right ventricle (RV) dysfunction, pulmonary hypertension, and corpulmonale. ${ }^{2,3)} \mathrm{We}$ reported that some children who were scheduled for adenotonsillectomyalso experienced right heart dysfunction on echocardiography without clinical symptoms. ${ }^{4}$ Thus, we investigated whether T\&A could improve RV dysfunction in children with OSA using conventional and tissue Doppler echocardiography (TDE).
Corresponding author: Eun Jung Cheon, MD Department of Pediatrics, Konyang University College of Medicine, 158 Gwanjeodong-ro, Seo-gu, Daejeon 35365, Korea

Tel: +82-42-600-9230

Fax: +82-42-600-9090

E-mail: ejcheon000@kyuh.ac.kr https://orcid.org/0000-0003-3844-0864

Received: 14 March, 2018

Revised: 21 June, 2018

Accepted: 6 July, 2018
Copyright (c) 2018 by The Korean Pediatric Society

This is an open-access article distributed under the terms of the Creative Commons Attribution NonCommercial License (http://creativecommons.org/ licenses/by-nc/4.0// which permits unrestricted noncommercial use, distribution, and reproduction in any medium, provided the original work is properly cited. 


\section{Materials and methods}

\section{Subjects}

The study was conducted at the Departments of Pediatric Cardiology and Otolaryngology, Konyang University Hospital, from June 2014 to July 2015. Out of 104 children scheduled for adenoidectomy during this period, only children who had OSA caused by ATH were included. Thirty-seven children who underwent echocardiography before and after adenotonsillectomy were included. According to the method of Cohen and Konak ${ }^{5)}$ and on the Brodsky scale, ${ }^{6}$ adenoid and tonsil of grades III-IV have been considered to be severe ATH, respectively. We verified OSA using the STOP (snoring-tiredness during the daytime-observed apnea-high blood pressure) questionnaire revised for children. Whether children had adenotonsillectomy was determined by an otolaryngologist and was based on careful examination and detailed medical history. This study was approved by the Institutional Review Board (IRB) of Konyang University Hospital (approval number: 2018-10-015). Informed consent was exempted by the IRB.

\section{Echocardiographic examination}

All children underwent transthoracic echocardiography conducted by a single pediatric cardiologist before and at least 12 months after adenotonsillectomy. The echocardiogram was obtained in all standard precordial positions via a 3- to 5-MHz transducer of Vivid E9 (General Electric, Oslo, Norway) using 2-dimensional, M-mode, conventional, and tissue Doppler examination according to the American Echocardiography Association guidelines. ${ }^{8)}$ For each parameter, the average of 5 consecutive cycles was taken.

\section{1) Pulmonary artery pressure}

A pulsed wave Doppler of pulmonic forward flow was obtained at the end of expiration, just proximal to the pulmonary valve in the parasternal short axis view. Right ventricular outflow tract (RVOT) acceleration time (AT) was measured from the beginning of the flow to the peak flow velocity (Fig. 1).

We calculated mean pulmonary artery pressure (mPAP) using the formula: $\mathrm{mPAP}(\mathrm{mmHg})=90-(0.62 \times A T R V O T) .{ }^{9,10)}$ We verified the presence and the maximal velocity of tricuspid regurgitation (TR) for all subjects.

\section{2) Tricuspid annular plane systolic excursion}

Tricuspid annular plane systolic excursion (TAPSE) was measured using the M-mode recordings from the apical 4-chamber view with the cursor placed on the free wall side of the tricuspid annulus ${ }^{11)}$ (Fig. 2) and was presented as a $z$ score adjusted by age. ${ }^{12)}$

3) Myocardial performance index of right ventricle

Myocardial performance index of right ventricle (RVMPI) was calculated, as described by Tei, ${ }^{13)}$ as the sum of the isovolumetric contraction and isovolumetric relaxation times divided by ejection

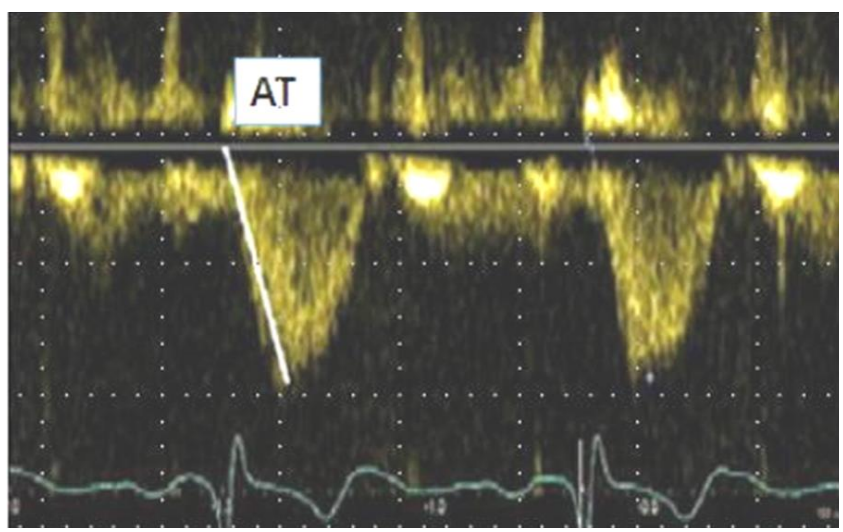

Fig. 1. Estimation of mean pulmonary artery pressure using right ventricular outflow tract acceleration time (AT).

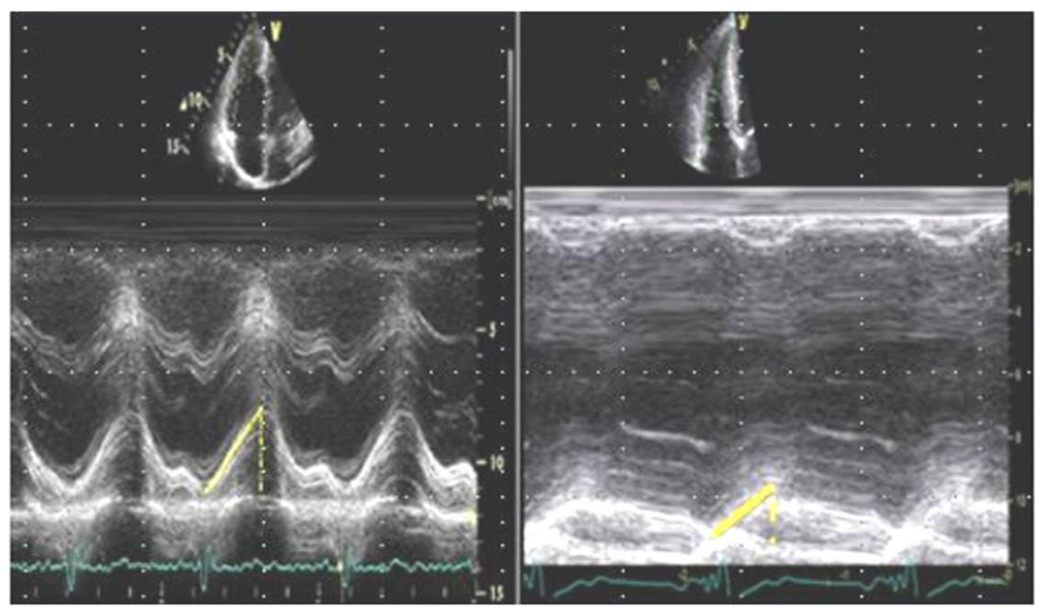

Fig. 2. Tricuspid annular plane systolic excursion (TAPSE) measured using M-mode echocardiography from the apical 4 chamber view with the cursor placed on the free wall side of the tricuspid annulus TAPSE. 
time. This was performed with TDE (Fig. 3).

Random echocardiography recordings were analyzed to determine the intraobserver variability before the study. Intraobserver variabilities were $<5 \%$ for all echocardiographic parameters.

\section{Statistical analysis}

We analyzed data using the PASW Statistics ver. 18.0 (SPSS Inc., Chicago, IL, USA). Continuous variables are presented as mean \pm standard deviation (median). The significance of the differences in the categorical variables between the groups was analyzed using the chi-square analysis; whereas, the significance of the differences in the continuous variables was evaluated using the Mann-Whitney $U$ test. A $P$ value $<0.05$ was considered significant.

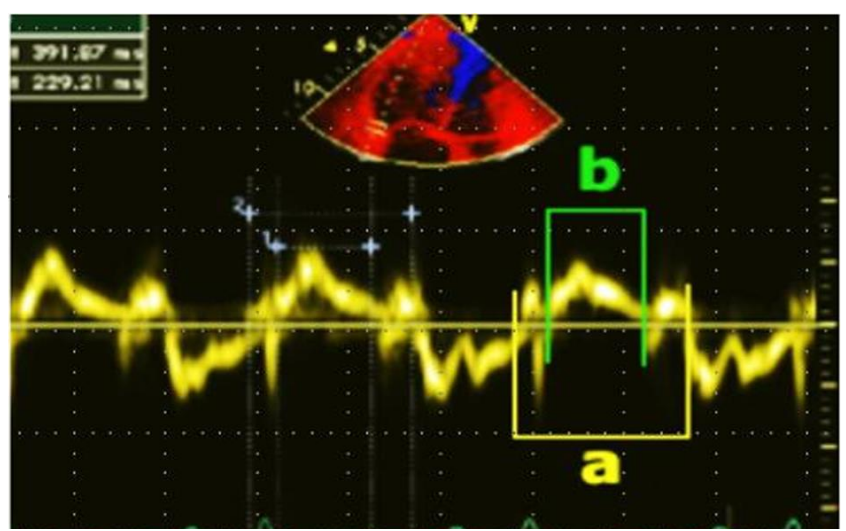

Fig. 3. Myocardial performance index of right ventricle (RVMPI) was calculated as described by as the sum of the isovolumetric contraction and isovolumetric relaxation times divided by the ejection time. RVMPI= $(a-b) / b$.

Table 1. Clinical characteristics of subjects before and after adenotonsillectomy

\begin{tabular}{lccr}
\hline Characteristic & Pre-T\&A & Post-T\&A & $P$ value \\
\hline Age $(\mathrm{yr})$ & $7.72 \pm 2.22(7.0)$ & $9.52 \pm 2.20(9.3)$ & $<0.01$ \\
BMl $\left(\mathrm{kg} / \mathrm{m}^{2}\right)$ & $17.8 \pm 3.5(17.4)$ & $19.2 \pm 3.5(19.0)$ & 0.02 \\
Percentile & $58.6 \pm 31.6(62.0)$ & $56.5 \pm 34.4(57.0)$ & 0.24 \\
z score & $0.90 \pm 1.14(0.93)$ & $0.8 \pm 1.19(0.83)$ & 0.16 \\
BSA $\left(\mathrm{m}^{2}\right)$ & $1.02 \pm 0.24(0.92)$ & $1.12 \pm 0.24(1.1)$ & 0.07 \\
Heart rate $(/ \mathrm{min})$ & $100.1 \pm 13.8(98)$ & $98.1 \pm 12.62(102)$ & 0.46 \\
SBP & $99.6 \pm 8.2(100)$ & $100.2 \pm 13.4(102)$ & 0.78 \\
Percentile & $53.8 \pm 24.9(51.4)$ & $51.3 \pm 25.2(50.6)$ & 0.15 \\
DBP & $62.4 \pm 4.1(61.2)$ & $61.9 \pm 9.2(60.0)$ & 0.64 \\
Percentile & $68.7 \pm 13.6(70.9)$ & $62.8 \pm 19.8(64.0)$ & 0.45 \\
\hline
\end{tabular}

Values are presented as mean \pm standard deviation (median).

T\& A, adenotonsillectomy; BMI, body mass index; BSA, body surface area; SBP, systolic blood pressure; DBP, diastolic blood pressure.

\section{Results}

The clinical characteristics of children before and after adenotonsillectomy are shown in Table 1. Age, weight, height, body surface area, and body mass index (BMI) increased postoperatively, which seems to be caused by a change by age. There was no significant difference between heart rate, BMI, and $z$ score.

The mPAP was normal in children with ATH and there was no difference between pre- and post-T\&A results. TR was observed in 17 children before surgery and in 15 patients after surgery. There was no significant difference in the maximal velocity of TR (TRmax) pre- and postsurgically ( $P=0.78$ ) (Table 2 ).

The absolute value of TAPSE increased $(21.45 \pm 0.90 \mathrm{~mm}$ vs. $22.30 \pm 1.10 \mathrm{~mm}, P=0.001$ ) after T\&A, but this change was noted because of growth. The $z$ score of TAPSE did not differ between preand post-T\&A (1.19 \pm 0.34 vs. $1.24 \pm 0.30, P=0.194$ ) (Fig. 4).

The value of RVMPI by TDE significantly improved after surgery (42.18 \pm 0.33 vs. $40.08 \pm 0.30, P=0.001$ ) (Fig. 5).

\section{Discussion}

ATH is the most common cause of upper respiratory tract obstruction and sleep apnea in children. ${ }^{14)}$ Prolonged upper airway obstruction during sleep leads the significant problems such as

Table 2. mPAP and TRmax preoperatively and postoperatively

\begin{tabular}{lccc}
\hline Variable & Pre-T\&A & Post-T\&A & $P$ value \\
\hline mPAP $(\mathrm{mmHg})$ & $19.6 \pm 3.40(18.7)$ & $18.7 \pm 2.68(17.9)$ & 0.06 \\
TRmax $(\mathrm{m} / \mathrm{sec})$ & $2.1 \pm 0.18(2.2)$ & $2.0 \pm 0.14(2.1)$ & 0.47 \\
\hline
\end{tabular}

Values are presented as mean \pm standard deviation (median).

mPAP, mean pulmonary artery pressure; TRmax, the maximal velocity of tricuspid regurgitation; $T \& A$, adenotonsillectomy.

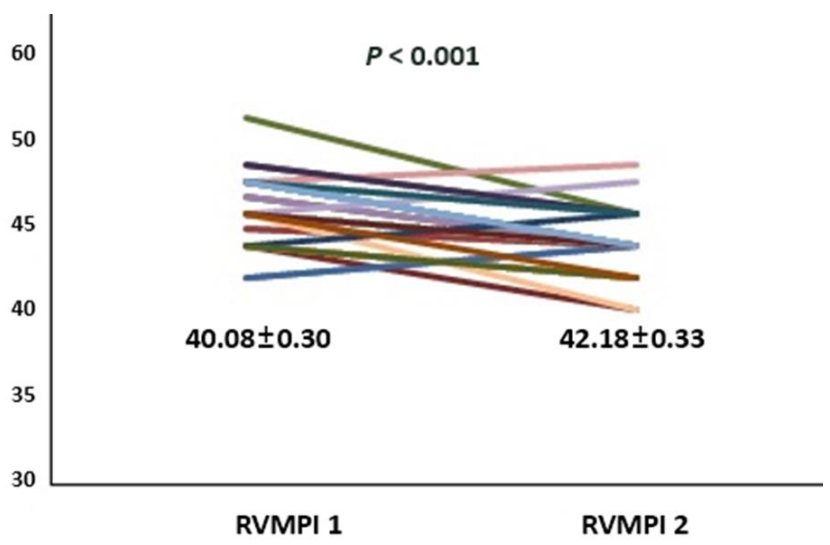

Fig. 4. Improvement of RVMPI before and after surgery in children who underwent T\&A. T\&A, adenotonsillectomy; RVMPI, myocardial performance index of the right ventricle; RVMPI 1, RVMPI 1 before T\&A; RVMPI2, RVMPI after T\&A. 


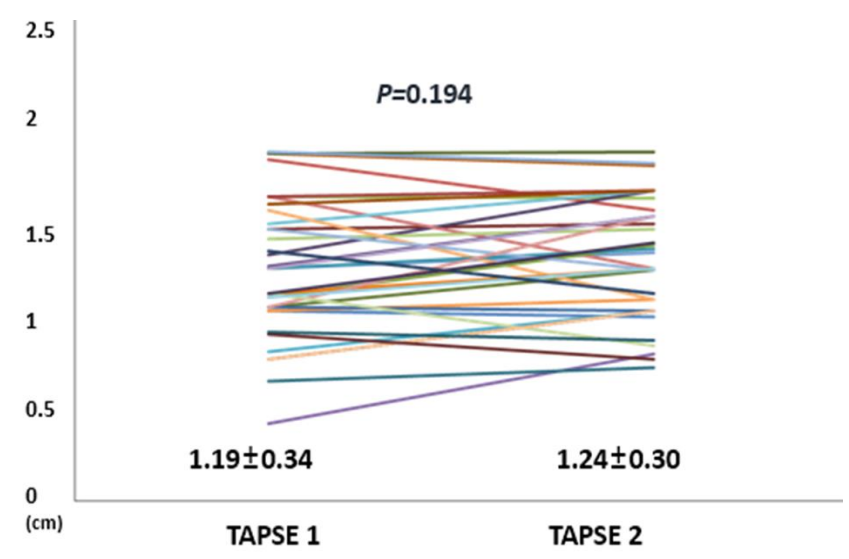

Fig. 5. The $Z$ score of TAPSE before and after surgery in children who underwent T\&A. T\&A, adenotonsillectomy; TAPSE, tricuspid annular planse systolic excursion; TAPSE 1, TAPSE before T\&A; TAPSE 2, TAPSE after T\&A.

hypersomnolence, emotional lability, decreased attention, small stature, enuresis, and cardiopulmonary morbidity. ${ }^{15,16)} \mathrm{T} \& \mathrm{~A}$ has been considered to be the first line of treatment which could improve the quality of life of children for pediatric OSA. Recently, there are many reports that shows marked improvements in right ventricular function, following the surgery in children with ATH.

According to the study by Acar et al. ${ }^{17)}$ the TAPSE value was lower than normal, and elevated 3 months after T\&A in children with ATH. TAPSE, which is easy and fast to perform, provides information about the right ven $\neg$ tricular systolic functions. Schmid et al. ${ }^{18)}$ found that the TAPSE value of patients with severe interstitial lung diseases was significantly lower compared to that of the control group. In our study, the value of TAPSE significantly increased after T\&A, but this was a change as children grew up. There was no difference in the TAPSE $z$ value.

We obtained the mPAP using RVOT AT and TR peak velocity before and after T\&A. The mPAP of our patients was in normal range even preadenotonsillectomy and was not different significantly pre- and postadenotonsillectomy. However, Koc et al., ${ }^{2)}$ Görür et al., ${ }^{19)}$ and Naiboglu et al. ${ }^{20)}$ cited that mPAP levels was elevated in patients with ATH, the value of $\mathrm{mPAP}$ were $31 \pm 9 \mathrm{mmHg}$ and 26.3 $\pm 5.4 \mathrm{mmHg}$, respectively, that is to say, considerable pulmonary hypertension. By contrast there was not any changes of the right ventricular functionin the studies of Pac et al. ${ }^{21)}$ The cause of this varying result can be explained as follows. The severity of obsturctive sleep apnea-hypopnea syndrome (OSAHS) could not been quantified without polysomnography so there would be a difference in the severity of OSAHS between researchers. The duration of follow-up varied for each study and subjects may be heterogeneous.

Duman et al. ${ }^{22}$ also reported that the RVMPI was impaired in pediatric patients with advanced ATH and improved after T\&A. Similarly, Attia et al. ${ }^{23}$ reported that RV TDE-derived MPI was significantly higher in patients with ATH compared to the control group. We observed that only the value of RV MPI by TDE in has improved children with OSA via TEA.

Evaluation of right ventricular functions by echocardiography is somewhat difficult because of the complex structural geometry of the RV and changes in the contraction pattern. MPI by TDE can be easily measured from the valve annulus with pulsed wave TDE is not affected by cardiac geometry, cardiac rate, blood pressure, or ventricular geometry, as compared to conventional Doppler. SoRV MPI has been found to be clinically useful to define RV function. ${ }^{24)}$ MPI might be more accurate and reflective of overall cardiac dysfunction than systolic and diastolic measures alone. ${ }^{25)}$ As a result, this new modality might be more sensitive for detecting subclinical abnormalities. ${ }^{26,27)}$

In conclusion, we can say that OSA associated with marked ATH might cause RV dysfunction. Based on the results of this study, we deferred that RVMPI by TDE could be the earliest indicator that responds to a change of the RV function in children with OSA.

The follow-up period of our study was longer than that of other investigators. However, the number of subjects was small and the diagnosis of OSA was made without sleep polysomnography.

\section{Conflicts of interest}

No potential conflict of interest relevant to this article was reported.

\section{References}

1. Obstructive Sleep Apnea Syndrome. In: American Academy of Sleep Medicine, editor. The International Classification of Sleep Disorders. Rochester (MN): American Sleep Disorders Association, 2001:52-8.

2. Koc S, Aytekin M, Kalay N, Ozcetin M, Burucu T, Ozbek K, et al. The effect of adenotonsillectomy on right ventricle function and pulmonary artery pressure in children with adenotonsillar hypertrophy. Int J Pediatr Otorhinolaryngol 2012;76:45-8.

3. Kocabaş A, Salman N, Ekici F, Cetin I, Akcan FA. Evaluation of cardiac functions and atrial electromechanical delay in children with adenotonsillar hypertrophy. Pediatr Cardiol 2014;35:785-92.

4. Lee JH, Yoon JM, Lim JW, Ko KO, Choi SJ, Kim JY, et al. Effect of adenotonsillar hypertrophy on right ventricle function in children. Korean J Pediatr 2014;57:484-8.

5. Cohen D, Konak S. The evaluation of radiographs of the nasopharynx. Clin Otolaryngol Allied Sci 1985;10:73-8.

6. Brodsky L. Modern assessment of tonsils and adenoids. Pediatr Clin North Am 1989;36:1551-69.

7. Chung F, Yegneswaran B, Liao P, Chung SA, Vairavanathan S, Islam S, et al. STOP questionnaire: a tool to screen patients for obstructive sleep apnea. Anesthesiology 2008;108:812-21.

8. Pearlman AS, Gardin JM, Martin RP, Parisi AF, Popp RL, Quinones MA, et al. Guidelines for optimal physician training in echocardiography. Recommendations of the American Society of Echocardiography Committee for Physician Training in Echocardiography. Am J Cardiol 1987;60:158-63. 
9. Dabestani A, Mahan G, Gardin JM, Takenaka K, Burn C, Allfie A, et al. Evaluation of pulmonary artery pressure and resistance by pulsed Doppler echocardiography. Am J Cardiol 1987;59:662-8.

10. Chemla D, Castelain V, Humbert M, Hébert JL, Simonneau G, Lecarpentier Y, et al. New formula for predicting mean pulmonary artery pressure using systolic pulmonary artery pressure. Chest 2004; 126:1313-7.

11. Rudski LG, Lai WW, Afilalo J, Hua L, Handschumacher MD, Chandrasekaran K, et al. Guidelines for the echocardiographic assessment of the right heart in adults: a report from the American Society of Echocardiography endorsed by the European Association of Echocardiography, a registered branch of the European Society of Cardiology, and the Canadian Society of Echocardiography. J Am Soc Echocardiogr 2010;23:685-713.

12. Koestenberger M, Ravekes W, Everett AD, Stueger HP, Heinzl B, Gamillscheg A, et al. Right ventricular function in infants, children and adolescents: reference values of the tricuspid annular plane systolic excursion (TAPSE) in 640 healthy patients and calculation of z score values. J Am Soc Echocardiogr 2009;22:715-9.

13. Tei C. New non-invasive index for combined systolic and diastolic ventricular function. J Cardiol 1995;26:135-6.

14. Ramakrishna S, Ingle VS, Patel S, Bhat P, Dada JE, Shah FA, et al. Reversible cardio-pulmonary changes due to adeno-tonsilar hypertrophy. Int J Pediatr Otorhinolaryngol 2000;55:203-6.

15. Sie KC, Perkins JA, Clarke WR. Acute right heart failure due to adenotonsillar hypertrophy. Int J Pediatr Otorhinolaryngol 1997;41: 53-8.

16. Mahajan M, Thakur JS, Azad RK, Mohindroo NK, Negi PC. Cardiopulmonary functions and adenotonsillectomy: surgical indications need revision. J Laryngol Otol 2016;130:1120-4.

17. Acar OÇ, Üner A, Garça MF, Ece İ, Epçaçan S, Turan M, et al. The effect of tonsillectomy and adenoidectomy on right ventricle function and pulmonary artery pressure by using Doppler echocardiography in children. Clin Exp Otorhinolaryngol 2016;9:163-7.
18. Schmid E, Hilberath JN, Blumenstock G, Shekar PS, Kling S, Shernan SK, et al. Tricuspid annular plane systolic excursion (TAPSE) predicts poor outcome in patients undergoing acute pulmonary embolectomy. Heart Lung Vessel 2015;7:151-8.

19. Görür K, Döven O, Unal M, Akkuş N, Ozcan C. Preoperative and postoperative cardiac and clinical findings of patients with adenotonsillar hypertrophy. Int J Pediatr Otorhinolaryngol 2001;59:41-6.

20. Naiboglu B, Deveci S, Duman D, Kaya KS, Toros S, Kinis V, et al. Effect of upper airway obstruction on pulmonary arterial pressure in children. Int J Pediatr Otorhinolaryngol 2008;72:1425-9.

21. Pac A, Karadag A, Kurtaran H, Aktas D. Comparison of cardiac function and valvular damage in children with and without adenotonsillar hypertrophy. Int J Pediatr Otorhinolaryngol 2005;69:527-32.

22. Duman D, Naiboglu B, Esen HS, Toros SZ, Demirtunc R. Impaired right ventricular function in adenotonsillar hypertrophy. Int J Cardiovasc Imaging 2008;24:261-7.

23. Attia G, Ahmad MA, Saleh AB, Elsharkawy A. Impact of obstructive sleep apnea on global myocardial performance in children assessed by tissue Doppler imaging. Pediatr Cardiol 2010;31:1025-36.

24. Cacciapuoti F. Echocardiographic evaluation of right heart function and pulmonary vascular bed. Int J Cardiovasc Imaging 2009;25:68997.

25. Tei C, Nishimura RA, Seward JB, Tajik AJ. Noninvasive Dopplerderived myocardial performance index: correlation with simultaneous measurements of cardiac catheterization measurements. J Am Soc Echocardiogr 1997;10:169-78.

26. Koç F, Tokaç M, Kaya C, Kayrak M, Yazıcı M, Karabağ T, et al. Diastolic functions and myocardial performance index in obese patients with or without metabolic syndrome: a tissue Doppler study. Turk Kardiyol Dern Ars 2010;38:400-4.

27. Abd El-Moneim ES, Badawy BS, Atya M. The effect of adenoidectomy on right ventricular performance in children. Int J Pediatr Otorhinolaryngol 2009;73:1584-8. 